\title{
Modeling and Control of a Two Wheeled Auto- Balancing Robot: a didactic platform for control engineering education
}

\author{
Fabián R. Jiménez L., MSc. ${ }^{1}$, Ilber A. Ruge R., MSc. ${ }^{2}$, and Andrés F. Jiménez L., PhD ${ }^{3}$ \\ 1,2 Pedagogical and Technological University of Colombia - Department of Electronic Engineering - I2E Research Group, \\ Tunja, Colombia. \{fabian.jimenez02, ilber.ruge\}@uptc.edu.co, 3Universidad de los Llanos - Faculty of Sciences and \\ Engineering, Villavicencio, Colombia, ajimenez@unillanos.edu.co.
}

\begin{abstract}
This paper describes the modeling, instrumentation and control of a Two Wheeled Automatic Balancing Robot (TWABR). This mechatronic system has two independently driven wheels to balance in the gravity center above the axis of the wheels' rotation. Its dynamic behavior has also served to illustrate fundamental concepts of stability, nonlinear dynamics, and modern control theory. The TWABR was designed using the ESP32 microcontroller as a digital control unit and the MPU6050 Inertial Measurement Unit as the main sensor. The dynamic model of the TWABR was analyzed through its representation in nonlinear differential equations and its linearized representation in the state space. With the linearized mathematical model around the equilibrium point, a classic PID controller and an optimal LQR controller were designed and simulated. The control objective was to balance the TWABR in the vertical equilibrium position, even when it is subjected to disturbances. The two control algorithms were simulated in the Matlab ${ }^{\circledR}$ / Simulink ${ }^{T M}$ software platforms and implemented digitally on the physical TWABR system. As a result, the experimental comparison of the performance of the implemented controllers was performed, where its stabilization, control robustness and adequate dynamic response at the equilibrium point of the TWABR were evaluated.
\end{abstract}

Keywords-States Space Model, Automatic Balancing Robot, Digital Control, PID and LQR Controllers.

\section{INTRODUCTION}

The Two Wheeled Automatic Balancing Robot (TWABR) is an unstable and non-linear electromechanical system consisting of two side wheels that have contact with the floor surface. The wheels are independently driven to balance in the gravity center above the axis of the wheels' rotation [1,2].

The wheels are driven by two motors coupled to each of them. The motors can be of a DC nature and are controlled by electrical signals by means of a control system based on the inclination reading and the velocity of their gravity center. Its operation is similar to the classic inverted pendulum system.

The control objective is to stabilize the TWABR by keeping it in a vertical equilibrium position, as shown in Fig. 1. The complex dynamics inherent in this platform finds its application in the design and development of control systems for cars, spacecraft, domestic transportation, military transport, among others [3-8].

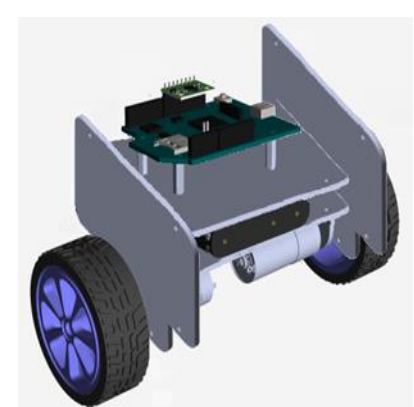

a)

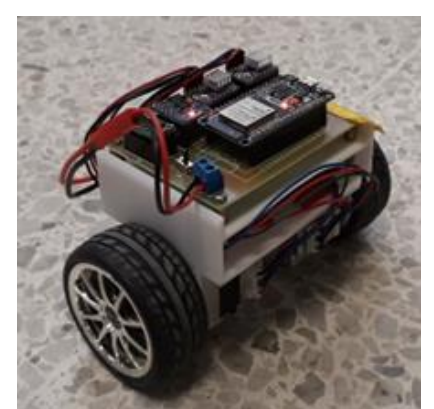

b)
Fig. 1 Two Wheeled Automatic Balancing Robot (TWABR). a) TWABR Designed. b) TWABR Implemented.

In recent years, the TWABR platform has had specific developments and applications such as: means of transporting passengers in short stretches within cities [3] for example, the modern Segway or Hoverboard vehicles; robotic assistance platforms for people with disabilities [4-6]; transporting means of baggage [7], and transport of objects to reduce human efforts in workplaces [8], domestic applications or hazardous work environments [9], among others.

Some of the advantages of this robotic platform are: small size, simple and compact structure, action flexibility, good maneuverability and low cost $[7,10]$. Additionally, it's an ecological alternative of mobility, since it works with electric energy that reduces the pollution produced by automobiles in the case of urban transport.

The motivation for working with the TWABR platform came from the fact that it's an interesting plant to control, not only because of its unstable and non-linear nature, but also because of its application outside the academic environment.

Its characteristics allowed the study and analysis of digital control systems inside the framework of the development of the integrating project developed by students of the Digital Control course in the Electronic Engineering Program of the Pedagogical and Technological University of Colombia.

An integrating project challenged the students of the Digital Control course to carry out the study of control problems and the verification of concepts related to the modeling of systems with non-linear dynamics, stability analysis, linearization, feedback control systems, robotics application and design of control systems. 
The main control problems of the TWABR are tilting, stabilization and tracking [11-17]. In this work the analysis of the problem of the balance and stabilization of the physical platform in the face of disturbances was raised, but other works such as [11-13], present approaches to achieve trajectory tracking for this system in real time.

In this document the information was organized in the following way: in section II describes the hardware components selection and its features, electronic instrumentation and the physical prototype construction of the TWABR. Section III describes the mathematical model obtained of the open-loop TWABR system based on the analysis of Nonlinear Ordinary Differential Equations. Then, the system linearization around the equilibrium point is presented, and finally, from the representation of the linearized system in the state space its transfer function is obtained [1822].

Section IV discusses the controllers design to stabilize the TWABR in its equilibrium point. Two controllers were designed: a classic PID (Proportional Integral Derivative) controller and an optimal controller LQR (Linear Quadratic Controller) with the help of Matlab ${ }^{\circledR} /$ Simulink $^{\mathrm{TM}}$ software platform. The designed controllers were simulated to verify and validate the response of the proposed control schemes [23 - 31]. Finally, the results of the implementation of the digital control algorithms in the ESP32 microcontroller, where the real responses of the controlled TWABR system are compared with the simulation responses.

\section{HARDWARE DESCRIPTION OF THE TWABR PROTOTYPE}

The implemented TWABR system (Fig. 1b) was conceived having the general structure shown in the block diagram of Fig. 2 that integrates six main modules: Control Module, Sensing Module, Actuation Module, Communication Module, Visualization Module and Power Supply Module.

The Control Module is composed by the MicroController Unit (MCU) that executes the digital control algorithm. The MCU receives the actual position signal from the Sensing Module and compares it with the TWABR position reference signal. The MCU calculates the error signal and enables the PID or LQR digital algorithms and generates the control signals to balance the TWABR system.

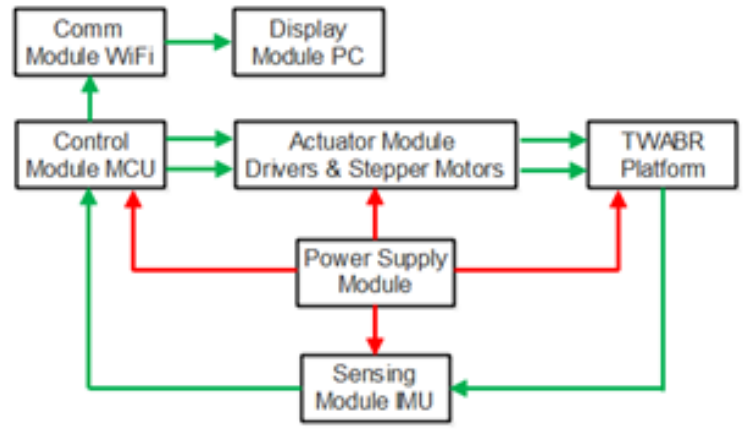

Fig. 2 Block Diagram of the Prototype TWABR.
The control signals enter to the Actuation Module to deliver the power to move the motors coupled to the wheels that balancing the system. The Sensing Module is the sensor that measures the actual position of the TWABR and delivers the position variable conditioned to the Control Module. The Actuation Module is composed of the drivers of the motors, the motors and the wheels.

The drivers receive the control signals from the Control Module to feed the motors. The Communication Module receives and transmits wirelessly the interest signals of the system to the visualization module. The Visualization Module receives the interest signals in real time and displays them on a screen.

The variables displayed on the screen stablish the actual behavior of the TWABR system. The Power Supply Module is the battery that feeds the electronic circuits of the Control, Sensing, Actuation and Communication modules.

\section{A. TWABR Prototype Car Body}

The TWABR system was built on an acrylic car body one eighth inch thick, designed and molded as shown in Fig. 3a. The rigid car body (Fig. 3b (1)) had dimensions of $12 \mathrm{~cm}$ in length, $15 \mathrm{~cm}$ in width and $10 \mathrm{~cm}$ in height, and was assembled with two levels to house the battery of the power supply (Fig. 3b (2)) and the module and the electronic circuits of the control, sensing, actuation and communication modules (Fig. 3b (3)). The stepper motors (Fig. 3b (4)) coupled to the wheels (Fig. 3b (5)) were secured over the TWABR car body.

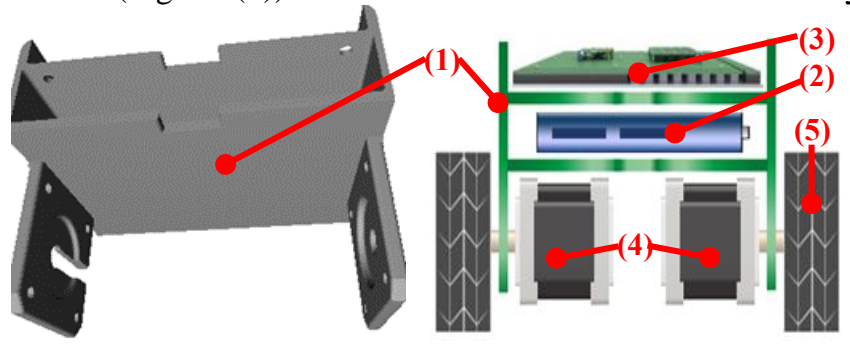

a)

b)

Fig. 3 a) Acrylic car body containing the modules of the TWABR system. b) Front view of the TWABR system design.

The arrangement of the TWABR modules in the car body is shown in Fig. 3 (b). The rear section of the robot body was cut to reduce its relative weight. The wheels were mounted at the bottom, under the control and processing module cards. The platform's stability point was adjusted by placing additional material on the lateral sides of the car body to ensure a uniform system weight.

\section{B. Control Module}

An ESP32 series MCU from the manufacturer Espressif ${ }^{\circledR}$ was used as the main element of the control module. Its processing speed, memory capacity and peripherals made this MCU appropriate for the application, with advantages such as good performance, robustness and reliability. The functional internal blocks of the ESP32 microcontroller board are illustrated in Fig. 4. 


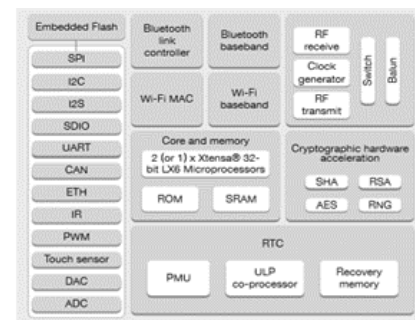

a)

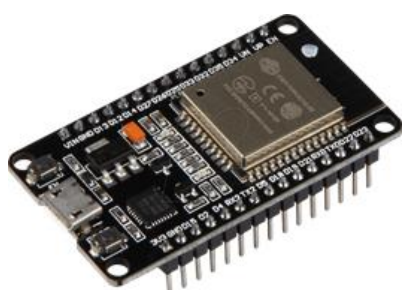

b)
Fig. 4. a) Functional Blocks Diagram of the ESP32 control module [32]. b) ESP32 control card.

The characteristics of the ESP32 MCU [32] used for processing and control of the TWABR system are described below:

1) $C P U$ : This MCU integrates two 32-bit Xtensa LX6 microprocessors and operates at processing speeds of up to $160 \mathrm{MHz}$. It has a 16-bit and 24-bit instruction set that supports digital signal processing functions and 32 interrupt vectors that They can generate internal or external interrupt routines from 70 different sources.

2) Internal Memory: it has $520 \mathrm{~KB}$ of RAM, integrated ROM of $448 \mathrm{~KB}$ and includes $16 \mathrm{~KB}$ in the RTC (Real Time Clock). In addition, it supports up to 8 MBytes of external SPI RAM.

3) $I^{2} \mathrm{C}$ Communication Interface: it has two physical $\mathrm{I}^{2} \mathrm{C}$ buses that can be configured as slaves or masters, in standard $100 \mathrm{Kbit} / \mathrm{s}$ mode or $400 \mathrm{Kbit} / \mathrm{s}$ fast mode. Used to connect external peripherals to the MCU. It supports $5 \mathrm{MHz}$ frequencies depending on the configuration of the SDA data line with pull-up resistors and 7-bit and 10-bit addressing modes. This interface was necessary in the project to communicate the control module with the sensing module.

4) PWM Output Port: the ESP32 MCU has output 16 channels for pulse width modulation, which is used to control motors and smart lights. Internally it is composed of synchronous or independent timers and a dedicated capture module that detects external events by flank or logical level change with exact timing. In the project this tool was used to generate variable frequency PWM signals to control the stepper motors of the TWABR actuation module.

5) Wi-Fi Wireless Connectivity: it has Wi-Fi and Bluetooth functions with implemented TCP/IP Internet protocol and $802.11 \mathrm{~b} / \mathrm{g} / \mathrm{h}$ full wireless communication protocol that offers a Basic Services Set (BSS) and a network administrator. This peripheral was used in the project as a communication module to transmit data from the TWABR to the computer in the visualization module through the UDP (User Datagram Protocol).

\section{Sensing Module}

The main element of the detection module was an Inertial Measurement Unit (IMU) based on the MPU6050 sensor of InvenSense MotionApps ${ }^{\mathrm{TM}}$ devices. This sensor combines a 3 axis gyroscope and a 3-axis accelerometer on the same chip, manufactured with MEM technology. This device integrates a
Digital Motion Processor (DMP) capable of performing complex motion capture algorithms of 9 degrees of freedom.

It communicates through the $\mathrm{I}^{2} \mathrm{C}$ interface compatible with the MCU of the control module and has the i2cdevlib library for immediate use. This sensor incorporates a $3.3 \mathrm{~V}$ voltage regulator and was connected in parallel through pull-up resistors connected to the Data and SCL pins of the $\mathrm{I}^{2} \mathrm{C}$ bus between the MCU and the IMU for direct use.

For accurate capture of fast and slow movements, it has a programmable scale range of 250/500/1000/2000 degrees/sec for the gyroscope and $2 \mathrm{~g} / 4 \mathrm{~g} / 8 \mathrm{~g} / 16 \mathrm{~g}$ for the accelerometer. It can be configured to transmit data at rates of up to $400 \mathrm{KHz}$. For the application, the sampling rate of the accelerometer and gyroscope was set at $8 \mathrm{KHz}$. Its installation was performed vertically on the TWABR basis as recommended by the manufacturer [33].

The gyroscope of the IMU detects the velocity of the angle in the three directions and the accelerometer detects the angular acceleration. Only the use of the $\mathrm{X}$ or $\mathrm{Y}$ axis reading was required for this application. By placing the sensor on the wheel axis, more accurate readings were obtained and the accelerations measured by the accelerometer were linear and proportional.

The sensor was mounted on a card and connected directly to the control module through the $\mathrm{I}^{2} \mathrm{C}$ pins as a slave mode, and its access was made by interruption. Fig. 5 shows the internal architecture of the IMU and the orientation of its recommended physical installation.

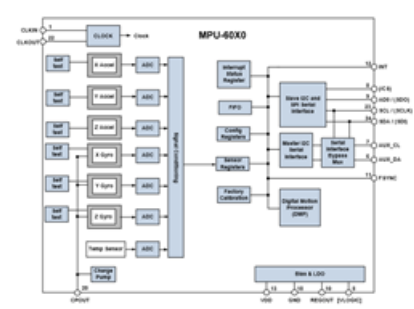

a)

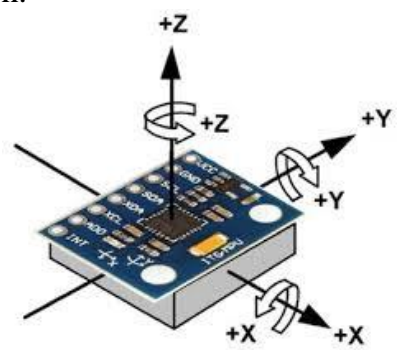

b)
Fig. 5. a) Block diagram of the IMU MPU 6050 [33]. b) Axes Orientation of the MPU 6050.

\section{Actuation Module}

This module consists of two drivers and two motors coupled to each wheel of the TWABR. Two independent bipolar stepper motors (two windings), manufactured by UsongShine®. Stepper bipolar motors of reference s17HS4401 and size NEMA-17 were used. These actuators are characterized by high output torque and excellent energy efficiency.

Fig. 6 shows the motor stepper used for the TWABR system, which works with pulses from $12 \mathrm{~V}$ to $1.2 \mathrm{~A}$, with an output torque that varies from $30 \mathrm{~N} / \mathrm{cm}$ to $60 \mathrm{~N} / \mathrm{cm}$, pitch angle $1.8^{\circ}$ and 200 steps per revolution [34]. Its rotation control clockwise or counterclockwise is carried out by means of the correct sequential polarization of the two windings and can reach a maximum rotation speed of $1000 \mathrm{rpm}$. 
This sensor operates with voltages between $2.3 \mathrm{~V}$ and 3.4 Volts, it has 6 ADC channels that go to a register, the $\mathrm{I}^{2} \mathrm{C}$ can also be monitored by means of an interruption.

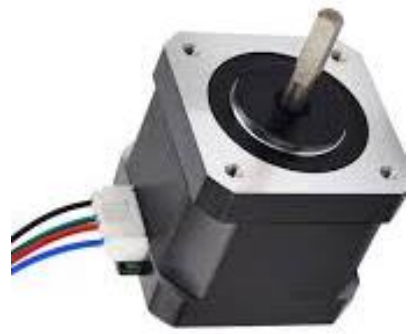

Fig. 6. Bipolar stepper motor used.

The current in each winding is a sequence of sine wave pulses, with $90^{\circ}$ phase shift between winding 1 and winding 2 . The pulses are delivered by the driver. The Texas Instruments DRV8825 integrated circuit was used as a micro-step driver [35]. In bipolar mode has resolutions from full step to $1 / 32^{\circ}$ step, with $11.1 \mathrm{~V}$ voltage supply at $1.5 \mathrm{~A}$, from the power supply module.

The driver receives PWM signals from the control module and delivers the signals in the form of bipolar periodic pulses to the windings of each stepper motor by means of a micropass indexer. The connectivity of the control module MCU with the DRV8825 driver is shown in Fig. 7a. The shape of the control PWM input pulses and the quantized current signals entering the bipolar stepper motors is illustrated in Fig. 7.

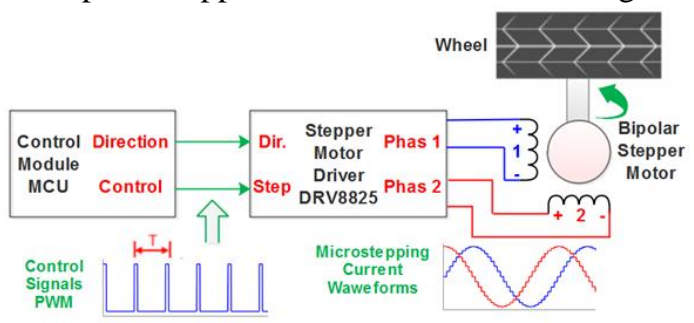

a)

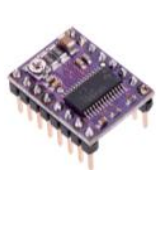

b)
Fig. 7. a) Control Module connection with the DRV 8825 driver of the Actuation Module. b) Driver Board DRV8825 [34].

The driver incorporates variable current sources and switches based on FET transistors that deliver the pulses in the correct sequence of electric current to the motor windings, turning the motor shaft step by step in a fixed amount (by configuring the STEP input), typically $1.8^{\circ}$ for a full step up to or $0.05625^{\circ}$ for a $1 / 32$ step operation. The driver contains a DIR input that determines the direction of rotation [35].

For example, for a half-step operation, to rotate the output shaft of the motor step by step $45^{\circ}$, the MCU of the control module is required to send 50 pulses to the motor circuit. If these 50 pulses are sent in 1 second $(50 \mathrm{~Hz})$, a rotation speed of $0.125 \mathrm{rev} / \mathrm{sec}$ (or $45^{\circ} / \mathrm{sec}$ ) is reached. If all 50 pulses are sent in 0.25 seconds $(200 \mathrm{~Hz})$, a rotation speed of $0.5 \mathrm{rev} / \mathrm{sec}$ $\left(180^{\circ} / \mathrm{sec}\right)$ is obtained.

Therefore, the rotation speed of the output shaft of the stepper motor is proportional to the frequency of the step control. The rotation speed of the TWABR system did not require a wheel rotation speed greater than 5 revolutions per second (300 rpm) to keep the robot in an upright position, so it was considered modeling the stepper motor as a first order system whose output torque is constant and the rotation velocity is proportional to the control signal frequency $\left(f_{P W M}\right.$ in Fig. 7a).

Let $\theta_{\text {step }}$ be the step angle and $f_{P W M}$ the frequency of the PWM pulses applied to the STEP input of the driver, $\theta_{w h}$ the wheel angle and $\omega_{w h}$ the wheel angular velocity. Then, the input-output relationship for the stepper motor can be approximated as (1):

$$
\omega_{w h}=\frac{d \theta_{w h}}{d t} \cong \theta_{\text {step }} \cdot f_{P W M}
$$

The step angle $\theta_{\text {step }}$ will be positive when rotating clockwise direction and negative in counterclockwise direction. The two wheels (diameter $65 \mathrm{~mm}$ and width $28 \mathrm{~mm}$ ) are attached to the axis of each stepper motor and have a necessary grip to provide sufficient friction on the flat surface.

\section{E. Communication Module}

This module establishes a remote connection between the control module and a device connected to the Internet, such as the PC or a mobile phone, which acts as a visualization module. The communication module uses the Wi-Fi wireless communication block of the control module to connect the MCU node to the Internet with a PC. The MCU node is connected to an existing access point of a Wi-Fi network that is known as a station mode connection (STA). The wireless communication architecture in STA mode is shown in Fig. 8.

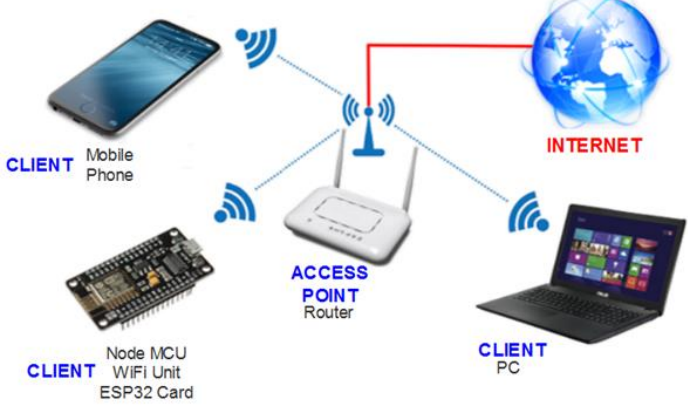

Fig. 8. STA architecture communication module TWABR system.

When the connection is established, two events are presented to the MC32 ESP32, SYSTEM_EVENT_STA_CONNECTED that indicates that it has connected to an access point and SYSTEM_EVENT_STA_GOT_IP that indicates that an IP has been assigned with the server of the access point.

This connection was used to transmit the control signal data from the control module to other client devices that connect to the same access point as the PC or a smartphone, taking advantage of the fact that the access point is connected to Internet (router).

In Station mode, the MCU node was connected to an Access Point, such as a router with its network name SSID 
(Service Set Identifier). In this mode, the MCU Node is integrated into the Wi-Fi network as a server/client, being able to interact with the rest of the devices that form it. The ESP8266WiFi.h library was used to establish and manage the connection. The WiFi.begin() function connects to the access point at a baud rate of 115.000 .

For connection management such as reconnection, disconnection or verification of the connection status was used the WiFi.reconnect() function. Also, to get information about the connection, such as the MAC or IP address, was used the WiFi.macAddress() command.

To connect the MCU node to the PC, the serial monitor of Matlab® was open called WiFi TCP/IP receive block, which receives data from the MCU via the wireless network. When a server's Connection Mode is configured, the local IP port is provided. The local IP port acts as a listening port on the TCP/IP server. When the client Connection Mode is configured, the remote IP address and the remote IP port must be provided on the TCP/IP server to receive data.

The block accepts data either in Blocking Mode or in Non-Blocking Mode. The block has two output ports, Data and Status. The Data port outputs requested data at each sample time. The Status port indicates whether the new data at the specified sample time is received.

\section{F. Visualization Module}

The TWABR system's signal display software platform was implemented in a user interface designed in a Matlab ${ }^{\circledR}$ Guide. The HMI interface allows students to observe the behavior of the controller by displaying in real time the set point, sensor input, error and PWM control signals, received by the WiFi TCP/IP receive block of Matlab®.

The Matlab ${ }^{\circledR}$ Guide shows in real time the interest variables of the TWABR and it is possible to select three digital control options: manual mode for control in open loop control, and PID and LQR for control in feedback loop.

\section{G. Power Supply Module}

It's a Lithium Polymer battery ( $\mathrm{Li}-\mathrm{Po})$ of $11.1 \mathrm{~V}$ with three $3 \mathrm{~S}$ cells for the power supply to the electronic cards of the control, sensing and actuation modules of the TWABR system. It was selected for its high performance, small size and $2000 \mathrm{mAh}$ capacity, appropriate to meet the power requirements of the system and ensure a 40-minutes autonomy under normal operating conditions. Motors are powered directly from the battery, and the module boards have $5 \mathrm{~V}$ and $3.3 \mathrm{~V}$ regulators for its operation.

\section{MATHEMATIC MODEL OF THE TWABR SySTEM}

The TWABR system is a dynamically unstable system [36] and has a behavior equivalent to an inverted pendulum on a cart with wheels, therefore, its modeled using as a reference to the inverted pendulum system [37]. The TWABR system can be considered as a mechanical platform composed of two coupled subsystems: the main body (pendulum) and the assembled rotation system (pendulum cart).
The main body resembles the inverted pendulum and integrates the chassis of the TWABR along with the control cards, drivers, battery and stators of the stepper motors. The main body is coupled to the rotation system and its mass $m_{B}$ is concentrated at its gravity center. The rotation system is equivalent to the inverted pendulum cart and is made up of the wheels and rotors of the stepper motors, as shown in the diagram in Fig. 9(a).

The coordinate system and the notation of the physical properties of the TWABR system are illustrated in the freebody diagram in Fig. 9(b) where the platform moves along a horizontal axis x. The tilt angle of the TWABR $\theta_{B}$ is the angle formed by the line that intersects the mass center of the main body and the axis of the wheel, with the $y$ axis.

The masses are measured using an electronic bascule and the individual and total moments of inertia are found using the Steiner theorem or parallels axis's theorem. The inertia moment of the rotation system $J_{R}$ is referenced with respect to the wheel's center, and the inertia moment of the main body $J_{B}$ is referenced on the axis of rotation with respect to the mass center.

In the free-body diagram in Fig. 9 (a) it is observed that a torque is applied to each TW wheel due to the movement of the stepper motors, making that the main body mass $m_{B}$ of the TWABR to shift, presenting the tilt angle $\theta_{B}$.
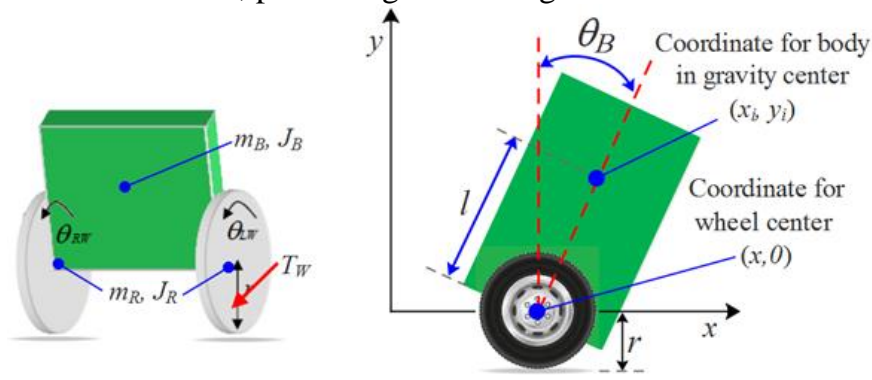

Fig. 9 Free-body diagram of the TWABR system a) Balanced. b) Inclined.

The measured and calculated physical parameters for the TWABR physical prototype are described in Table I.

TABLE I

PHYSICAL PARAMETERS OF THE IMPLEMENTED TWABR SYSTEM

\begin{tabular}{|c|l|c|c|}
\hline \multicolumn{2}{|c|}{ Parameter } & Value & Unit \\
\hline$r$ & Wheel Radius & 0.04 & $\mathrm{~m}$ \\
\hline$m_{R}$ & Mass of the Rotation system & 0.18 & $\mathrm{Kg}$ \\
\hline$J_{R}$ & Moment of inertia of the rotation system & 0.000025 & $\mathrm{kgm}^{2}$ \\
\hline$F_{R}$ & Friction Coefficient of the rotation system. & 0.2 & $\mathrm{Nrad}^{-1} \mathrm{~s}^{-1}$ \\
\hline$l$ & $\begin{array}{l}\text { Length measured from the wheel axis and } \\
\text { mass center of the main body. }\end{array}$ & 0.08 & $\mathrm{~m}$ \\
\hline$m_{B}$ & Mass of the main body & 1.16 & $\mathrm{Kg}^{2}$ \\
\hline$J_{B}$ & Moment of inertia of the main body & 0.0015 & $\mathrm{kgm}^{2}$ \\
\hline$F_{B}$ & Friction Coefficient of the main body & 0.002 & $\mathrm{Nrad}^{-1} \mathrm{~s}^{-1}$ \\
\hline$g$ & Gravitational acceleration of the Earth. & 9,807 & $\mathrm{~ms}^{-2}$ \\
\hline
\end{tabular}

To obtain the TWABR system model, the following considerations are assumed: 1) the wheels follow a non-slip movement, 2) the wheels of the rotation system are rigid and 
similar (same radius and masses) and 3) that the weight in the main body is evenly distributed. Frictions in movements are initially considered, but are later omitted.

\section{A. Dynamic model of the TWABR system}

The motion equations that define the behavior of the TWABR system can be obtained using the Lagrangian dynamics illustrated below based on the free-body diagram in Figure 9(b) [11,27,38, 39].

The kinetic energy of the rotation system due to angular displacement can be represented as:

$$
K \cdot E_{R}=\frac{1}{2} m_{R} \cdot x^{2}
$$

Where $x_{i}$ and $y_{i}$ coordinates indicate the position of the center of gravity of the main body:

$$
\begin{gathered}
x_{i}=x+l \cdot \sin \left(\theta_{B}\right) \\
y_{i}=l \cdot \cos \left(\theta_{B}\right)
\end{gathered}
$$

Calculating the derivatives of the previous position $\left(x_{i}, y_{i}\right)$ with respect to time, the respective velocities were found as:

$$
\begin{gathered}
v_{x_{1}}=x+l \cdot \cos \left(\theta_{B}\right) \\
v_{y_{i}}=-l \cdot \sin \left(\theta_{B}\right)
\end{gathered}
$$

Taking the squares of the main body velocities (pendulum):

$$
\begin{gathered}
\| v_{\mathrm{i}}^{2} \mid=v_{x_{\mathrm{i}}}{ }^{2}+v_{y_{\mathrm{i}}}{ }^{2}=\dot{x}^{2}+2 l x^{2} \theta_{B} \cos \left(\theta_{B}\right)+\cdots \\
\ldots+l^{2} \theta_{B}{ }^{2} \cos ^{2}\left(\theta_{B}\right)+l^{2} \theta_{B}{ }^{2} \sin ^{2}\left(\theta_{B}\right)
\end{gathered}
$$

Simplifying (5) using trigonometric identity:

$$
\left|v_{\mathrm{i}}^{2}\right|=\dot{x}^{2}+2 l x^{2} \theta_{B} \cos \left(\theta_{B}\right)+l^{2} \theta_{B}{ }^{2}
$$

Then the kinetic energy of the main body due to the linear displacement of the TWABR is obtained as:

$$
K \cdot E_{B}=\frac{1}{2} m_{B} \cdot \dot{x}^{2}+m_{B} l \dot{x}^{x} \theta_{B} \cos \left(\theta_{B}\right)+\frac{1}{2} m_{B} l^{2} \theta_{B}{ }^{2}
$$

Adding (2) and (7) the total kinetic energy of TWABR is obtained in (8):

$$
\begin{aligned}
E_{T}= & \frac{1}{2}\left(m_{B}+m_{R}\right) \cdot x^{2}+m_{B} l x^{x} \theta_{B} \cos \left(\theta_{B}\right)+\ldots \\
& { }_{-1}^{\frac{1}{2}}\left(l_{B}+m_{B} l^{2}\right) \theta_{B}{ }^{2}
\end{aligned}
$$

The general Lagrange equations for the velocity of the rotation system and the main body of the TWABR are calculated as follows:

$$
\begin{aligned}
& \frac{d}{d t}\left(\frac{\partial E_{T}}{\partial x}\right)-\frac{\partial E_{T}}{\partial x}=Q_{R} \\
& \frac{d}{d t}\left(\frac{\partial E_{T}}{\partial \theta}\right)-\frac{\partial E_{T}}{\partial \theta}=Q_{B}
\end{aligned}
$$

Deriving (8) to find $Q_{R}$ :

$$
\begin{gathered}
\frac{\partial E_{T}}{\partial \dot{x}}=\left(m_{B}+m_{R}\right) \cdot \dot{x}+m_{B} l \theta_{B} \cos \left(\theta_{B}\right) \\
\frac{d}{d t}\left(\frac{\partial E_{T}}{\partial \dot{x}}\right)=\left(m_{B}+m_{R}\right) \cdot \bar{x}+m_{B} l \theta_{B} \cos \left(\theta_{B}\right) \\
\frac{\partial E_{T}}{\partial x}=0 \Rightarrow Q_{R}=T_{W}-f_{R} \cdot \dot{x}
\end{gathered}
$$

$$
\begin{gathered}
\frac{\partial E_{T}}{\partial \theta}=m_{B} l \dot{x} \cos \left(\theta_{B}\right)+\left(j_{B}+m_{B} l^{2}\right) \theta_{B} \\
\frac{d}{d t}\left(\frac{\partial E_{T}}{\partial \theta}\right)=m_{B} l \bar{x} \cos \left(\theta_{B}\right)+\left(\gamma_{B}+m_{B} l^{2}\right) \theta_{B} \ldots \\
\frac{\partial E_{T}}{\partial \theta}=m_{B} l x_{B} \theta_{B}^{2} \sin \left(\theta_{B}\right) \\
Q_{B}=-m_{B} l x^{x} \theta_{B} \sin \left(\theta_{B}\right)
\end{gathered}
$$

Substituting the previous values in the Lagrange equations (9) and (10) is obtained the motion equations:

$$
\begin{aligned}
\ddot{x}= & -\frac{m_{B} l}{\left(m_{B}+m_{R}\right)}\left(\theta_{B} \cos \left(\theta_{B}\right)+\theta_{B}{ }^{2} \sin \left(\theta_{B}\right)\right)+\cdots \\
& =\frac{1}{\left(m_{B}+m_{R}\right)}\left(T_{W}-f_{R} \cdot \dot{x}\right) \\
\theta_{B}= & -\frac{m_{B} l}{\left(g_{B}+m_{B} l^{2}\right)}\left(\bar{x} \cos \left(\theta_{B}\right)+g \sin \left(\theta_{B}\right)\right)-\ldots \\
& \ldots-\frac{f_{B}}{\left(J_{B}+m_{B} l^{2}\right)} \theta_{B}
\end{aligned}
$$

Where (17) and (18) defines the non-linear dynamic behavior of the TWABR system. Equation (17) was obtained from the assembled rotation system, while (18) was obtained from the main body. The inputs to the TWABR system are the torque $T_{L \mathrm{~W}}$ and $T_{R \mathrm{~W}}$ applied to the left and right wheel assemblies by the stepper motors, which are assumed to be similar, that is: $T_{W}=T_{L \mathrm{~W}}=T_{\mathrm{RW}}$.

\section{B. Linearized TWABR Model in the State Space}

The motion equations (17) and (18) are linearized around the unstable equilibrium point of the system at $\theta_{B}=\theta_{B}=0$, since the desired operating point is considered when the TWABR system is in a stable vertical position, with angle zero tilt. In this sense, for an inclination angle $\theta \mathrm{B}$ zero, it implies making the following approximations for linearization: $\sin \left(\theta_{B}\right) \cong \theta_{B} ; \cos \left(\theta_{B}\right) \cong-1 ; \mathrm{y} \theta_{B}{ }^{2} \cong 0$.

Using the previous approaches to linearize (17) and (18) and making negligible the friction in the main body of TWABR $f_{B} \cong 0$, we have:

$$
\begin{gathered}
\dot{x}=\frac{m_{B} l}{\left(m_{B}+m_{R}\right)} \ddot{\theta}_{B}+\frac{1}{\left(m_{B}+m_{R}\right)}\left(T_{W}-f_{R} \cdot \dot{x}\right) \\
\theta_{B}=\frac{m_{B} l}{\left(g_{B}+m_{B} l^{2}\right)} \dot{x}+\frac{m_{B} l g}{\left(\jmath_{B}+m_{B} l^{2}\right)} \theta_{B}
\end{gathered}
$$

Substituting $\ddot{\theta}_{B}$ from (20) in (19) and solving for $\bar{x}$ is obtained (21):

$$
\underline{x}=\frac{\left(T_{W}-f_{R} \cdot \dot{x}\right)\left(j_{B}+m_{B} l^{2}\right)+m_{B}{ }^{2} l^{2} g \theta_{B}}{J_{B}\left(m_{B}+m_{R}\right)+m_{B} m_{R} l^{2}}
$$

Similarly, replacing $\bar{x}$ from (19) in (20) and solving for $\theta_{B}$ is obtained (22):

$$
\theta_{B}=\frac{m_{B} l\left(T_{W}-f_{R} \times \dot{x}\right)+m_{B} g\left(m_{B}+m_{R}\right) \theta_{B}}{J_{B}\left(m_{B}+m_{R}\right)+m_{B} m_{R} l^{2}}
$$

Similarly, deriving (8) to find $Q_{B}$ : 
In (21) and (22) the common denominator is called $p$ where $p=l_{B}\left(m_{B}+m_{R}\right)+m_{B} m_{R} l^{2}$, and simplify (21) and (22) in (23) and (24) respectively:

$$
\begin{gathered}
\ddot{x}=\frac{\left(T_{W}-f_{R} \cdot \dot{x}\right)\left(j_{B}+m_{B} l^{2}\right)+m_{B}{ }^{2} l^{2} g \theta_{B}}{p} \\
\ddot{\theta}_{B}=\frac{m_{B} l\left(T_{W}-f_{R} \cdot \dot{x}\right)+m_{B} g\left(m_{B}+m_{R}\right) \theta_{B}}{p}
\end{gathered}
$$

Then the state variables are: the horizontal position of the TWABR at the $x$ coordinate $x_{1}=x$; horizontal velocity of the TWABR at $x$ coordinate $x_{2}=x$; the angular position of the main body $x_{3}=\theta_{B}$; and the angular velocity of the main body $x_{4}=\theta_{B . ;}$. As input to the TWABR system, the torque applied to each of the wheels coupled to each stepper motor of the TWABR $u=T_{W}$ is proposed.

As outputs to control are: the horizontal position of the TWABR at the $x$ coordinate $y_{1}=x_{1}$ and the angular position of the main body of the TWABR $y_{2}=x_{3}=\theta_{B}$. Now, assuming that the used stepper motor has a constant output torque, it can be considered that what is going to be controlled is the angular velocity of the stepper motor output shaft that corresponds to the rotation velocity of each wheel $\theta_{W}$, which is related to the input motor torque according to the relationship (25):

$$
r \dot{\theta}_{W}=u(t)=T_{W}(t)
$$

The system representation in the state space is given as:

$$
\begin{aligned}
& \mathbb{Z}(t)=\mathbb{A X}(t)+\mathbb{B U}(t) \\
& \mathbb{Y}(t)=\mathbb{C X}(t)+\mathbb{D U}(t)
\end{aligned}
$$

Where the differential equation of the state variables of the linearized system around the operation point containing the state matrix $\mathbb{A}$ and the input matrix $\mathbb{B}$ shown in (26) an (27):

$$
\begin{gathered}
\operatorname{AX}(t)=\left[\begin{array}{cccc}
0 & 1 & 0 & 0 \\
0 & -\frac{f_{R}\left(U_{B}+m_{B} \mathbb{I}^{2}\right)}{p} \frac{m_{B}{ }^{2} \mathbb{I}^{2} g}{p} & 0 \\
0 & 0 & 1 & 0 \\
0 & -\frac{m_{B} 1 f_{R}}{p} \frac{m_{B} g\left(m_{B}+m_{R}\right)}{p} & 0
\end{array}\right] \cdot\left[\begin{array}{l}
x_{1} \\
x_{2} \\
x_{a} \\
x_{4}
\end{array}\right] \\
\mathbb{B U}(t)=\left[\begin{array}{c}
0 \\
\frac{J_{B}+m_{B} \mathbb{l}^{2}}{p} \\
0 \\
\frac{m_{B} \mathbb{l}}{p}
\end{array}\right] \cdot[u]
\end{gathered}
$$

The algebraic output equation containing the output matrix $\mathbb{C}$ and feedforward matrix $\mathbb{D}$ are described in (28):

$$
\mathbb{C X}(t)+\mathbb{D U}(t)=\left[\begin{array}{llll}
1 & 0 & 0 & 0 \\
0 & 0 & 1 & 0
\end{array}\right] \cdot\left[\begin{array}{l}
x_{1} \\
x_{2} \\
x_{\mathrm{a}} \\
x_{4}
\end{array}\right]+\left[\begin{array}{l}
0 \\
0
\end{array}\right] \cdot[u]
$$

\section{TWABR System Transfer Function}

The application of the Laplace transform to the differential equations of the TWABR system (19) and (20) is represented in the frequency domain by (31) and (32) to obtain its transfer function.

$$
\begin{gathered}
\left(m_{B}+m_{R}\right) \ddot{x}=m_{B} l \ddot{\theta}_{B}+\left(T_{W}-f_{R} \cdot \dot{x}\right) \\
\left(J_{B}+m_{B} l^{2}\right) \theta_{B}=m_{B} l \ddot{x}+m_{B} \lg \theta_{B}
\end{gathered}
$$

$$
\begin{gathered}
\left(m_{B}+m_{R}\right) s^{2} X(s)+f_{R} s X(s)-m_{B} l s^{2} \Theta_{B}(s)=\mathrm{T}_{W}(s) \\
\left(J_{B}+m_{B} l^{2}\right) s^{2} \Theta_{B}(s)-m_{B} l g \Theta_{B}(s)=m_{B} l s^{2} X(s)
\end{gathered}
$$

Clearing $X(s)$ from (32) is obtained (33) and replacing (33) in (31) we obtain the transfer function of the system that relates the output of the angular position $\Theta_{B}(s)$ with respect to the input torque $\mathrm{T}_{W}(s):$ :

$$
\begin{gathered}
X(s)=\left[\frac{\left.\bigcup_{B}+m_{B} l^{2}\right)}{m_{B} l}-\frac{g}{s^{2}}\right] \Theta_{B}(s) \\
\frac{\Theta_{B}(s)}{\mathrm{T}_{W}(s)}=\frac{\frac{m_{B} l s^{2}}{p}}{s^{4}+\frac{f_{R}\left(I_{B}+m_{B} l\right) s^{2}-m_{B} \lg \left(m_{B}+m_{R}\right) s^{2}-f_{R} m_{B} \lg s}{p}}
\end{gathered}
$$

After the cancellation of the pole and the zero at the origin and the term $\mathrm{p}$ of the denominator we obtain (36):

$$
\frac{\Theta_{B}(s)}{\mathrm{T}_{W}(s)}=\frac{m_{B} l s}{p s^{2}+f_{R}\left(g_{B}+m_{B} l\right) s^{2}-m_{B} l g\left(m_{B}+m_{R}\right) s-f_{R} m_{B} l g}
$$

Replacing the term $\mathrm{T}_{W}(s)=s r \Theta_{W}(s)$ of the relation (25) and if the friction of the assembled rotation system $f_{R} \cong 0$ is neglected, we obtain the simplified linear transfer function around the point of operation of the platform TWABR (37):

$$
\begin{gathered}
\frac{\Theta_{B}(s)}{s \Theta_{W}(s)}=\frac{r m_{B} l}{p s^{2}-m_{B} \lg \left(m_{B}+m_{R}\right)} \\
\frac{\Theta_{B}(s)}{\Theta_{W}(s)}=\frac{K_{T} s}{\frac{s^{2}}{A_{T}}-1}
\end{gathered}
$$

Equation (38) indicates that with proper adjustment of the angular velocity of the stepper motor output shaft $\dot{\theta}_{W}$, it is possible to keep $\theta_{B}$ close to zero degrees, that is, it places the system in a vertical position. Replacing the $\mathrm{p}$ term gives the location of the actual pair of $A_{T}$ poles of the TWABR system. One pole is located in the left half plane (stable) and the other in the right half plane (unstable) of the complex $S$-plane:

$$
\begin{gathered}
K_{T}=\frac{r}{g\left(m_{B}+m_{R}\right)} \\
A_{T}= \pm \sqrt{\frac{\left(m_{B}+m_{R}\right) / m_{R} g l}{\left(m_{B}+m_{R}\right)\left(I_{B}+m_{B} I^{2}\right)-\left(m_{B} I^{2}\right.}}
\end{gathered}
$$

\section{TWABR open circuit system without control}

By replacing in (38) the TWABR system parameters obtained in the Table I, the transfer function of the theoretical approximate model was obtained:

$$
\frac{\Theta_{B}(s)}{\Theta_{W}(s)}=\frac{0.7495 s}{s^{2}-27.93056}
$$

This transfer function indicates that the open loop system is unstable with two real poles located at $p_{1,2}= \pm 5.28$.

The non-linear and linearized model of the TWABR system is simulated against the step response to observe its open-loop behavior. The results obtained are shown in Fig. 10, 
which indicates that the system is unstable and a rapid increase in the exit angle is observed due to the small variation of the input signal.

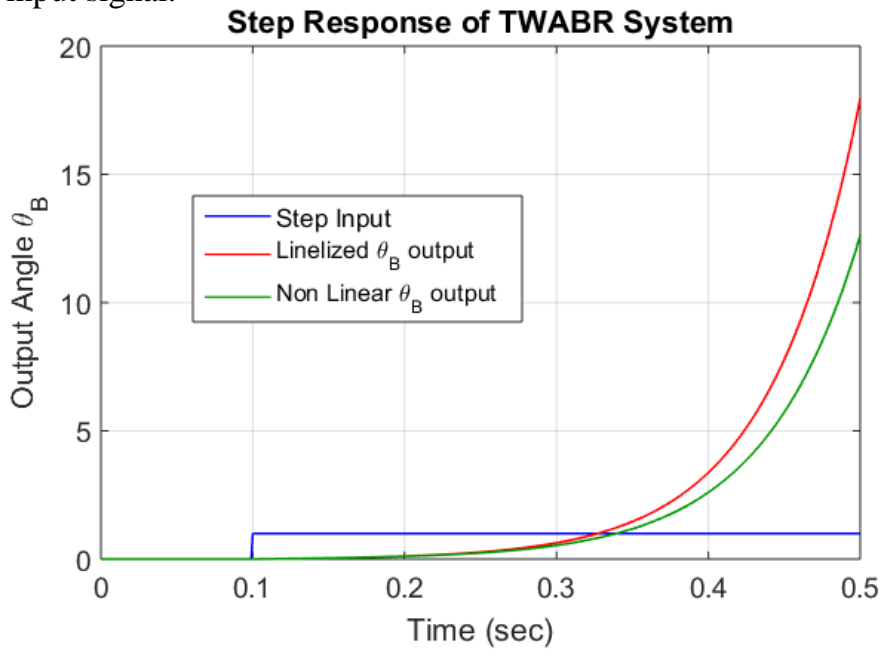

Fig. 10 Angular position $\theta_{B}$ of the nonlinear and linear model of TWABR.

\section{DESIGN OF DigITAL CONTROLLERS AND RESUltS ANALYSIS}

The TWABR system is not stable in open loop since, when a bounded input stimulus, the output of the inclination angle $\theta \mathrm{B}$ is not bounded, that is, it has a runaway response, due its model has a pole in the right of the complex s-plane.

The design of two controllers is proposed to be implemented digitally whose main purpose is to stabilize the system and keep it in the main body of the TWABR in vertical position at (desired operating point) where the tilt angle is $\theta_{B}=0$, regardless of the disturbances.

It was proposed to design a classic PID controller and a modern LQR controller, both of which were designed and simulated in Matlab $\AA$ and then be implemented as digital algorithms on the ESP32 microcontroller of the TWABR control module. From its implementation, the performance evaluation of each of the controllers was carried out.

To be evaluated the controllers, it was established the next design requirements: system stability against disturbances, establishment time less than 0.3 seconds and that the main body of the TWABR should not move more than $5^{\circ}$ (approximately 0.087 radians) from the vertical.

\section{A: PID Controller Design}

The PID controller has three control actions: the proportional control action $\left(K_{p}\right)$, the differential control action $\left(K_{d}\right)$ and the integral control action $\left(K_{i}\right)$ [40]. The PID control architecture is feedback where the input to the controller is the system error signal $e\left[n T_{m}\right]$. The error is the deviation between the desired state of the tilt angle $\theta_{B}=0$ and the state of the actual tilt angle measured by the IMU of the TWABR sensing module. The error signal enters to the three control actions simultaneously. The proportional control action $K_{p}$ causes the feedback system to reduce the angular position error, causing the motors to rotate in the same direction of movement of the system to prevent them from falling.

The integral control action $K_{i}$ averages past errors and significantly reduces the steady-state error by making the system perfectly follow the desired reference. The differential control action $K_{d}$ acts on the future of the error by predicting the error trend by damping the overshoots in the transient response and reducing TWABR vibrations.

The PID controller combines the control actions to calculate the final control value $u\left[n T_{m}\right]$ that delivers power to the TWABR system stepping motors through proportional PWM signals. The design objective is to calculate the gains of the control actions through of the control law delivered by the PID controller:

$$
u(t)=K_{p} e(t)+K_{\mathrm{i}} \int e(t) d t+K_{d} \frac{d e(t)}{d t}
$$

The PID was designed using the experimental ZieglerNichols self-sustaining oscillation tuning method, where the system was simulated and fed backed. Next the proportional gain was increased until the output oscillated in a sustained way. Using the critical oscillation gain obtained $K_{c}=246$ and the oscillation period $T_{c}=0.1 \mathrm{~s}$, the Ziegler-Nichols closedloop tuning table was used and gains were obtained for P, PI, PD and PID controllers. The PID controller was selected to implement due that was the one that presented the best performance. The PID controller gains were: $K_{p}=148$; $K_{i}=2960$ and $K_{d}=0.4$.

Applying Laplace transform to (41):

$$
U(s)=K_{\mathrm{p}} E(s)+\frac{K_{\mathrm{i}} E(s)}{s}+s K_{d} E(s)
$$

Dividing the control output $U(s)$ over the error input to controller $E(s)$ is obtained the ideal (improper) transfer function of the analog PID controller:

$$
G_{P I D}(s)=\frac{U(s)}{E(s)}=K_{p}+\frac{K_{i}}{s}+s K_{d}
$$

The digital PID controller was obtained through digitalization using the $K_{p}, K_{d}$ and $K_{i}$ analog gains obtained and by selecting a sampling period of $T_{m}=0.001 \mathrm{~s}$, to be implemented in discrete time. For this the term s of the integral action of (43) is replaced by the Tustin approximation and the term $s$ of the differential action of (43) by the backward differential approximation.

$$
\begin{gathered}
G_{P I D}\left(z, T_{m}\right)=K_{p}+\frac{K_{i}}{\frac{2(z-1)}{T_{m}(z+1)}}+\frac{(z-1)}{T_{m} z} K_{d} \\
=\frac{K_{p} z(z-1)+\frac{T_{m} z K_{i}}{2}(z+1)+\frac{(z-1)^{2} K_{d}}{T_{m}}}{z(z-1)} \\
=\frac{\left(K_{p}+\frac{T_{m} K_{i}}{2}+\frac{K_{d}}{T_{m}}\right) z^{2}+\left(\frac{T_{m} K_{i}}{2}-K_{p}-\frac{2 K_{d}}{T_{m}}\right) z+\frac{K_{d}}{T_{m}}}{z(z-1)}
\end{gathered}
$$

The PID digital transfer function is obtained in (45) by replacing the next terms. 


$$
\begin{gathered}
\alpha_{0}=\left(K_{p}+\frac{T_{m} K_{\mathrm{i}}}{2}+\frac{K_{d}}{T_{m}}\right) \\
\alpha_{1}=\left(\frac{T_{m} K_{\mathrm{i}}}{2}-K_{p}-\frac{2 K_{d}}{T_{m}}\right) y \alpha_{2}=\frac{K_{d}}{T_{m}} \\
G_{P I D}\left(z, T_{m}\right)=\frac{\alpha_{0} z^{2}+\alpha_{1} z+\alpha_{2}}{z(z-1)}
\end{gathered}
$$

The digital PID is its proper, taking it to negative powers of $z$ and decoupling the Error input and Control output, applying the Inverse $\mathrm{Z}$ Transform to obtain the recursive equation of the PID:

$$
\begin{gathered}
G_{P I D}\left(z, T_{m}\right)=\frac{U\left(z, T_{m}\right)}{E\left(z, T_{m}\right)}=\frac{\alpha_{0}+\alpha_{1} z^{-1}+\alpha_{2} z^{-2}}{1-z^{-1}} \\
U\left(z, T_{m}\right)\left(1-z^{-1}\right)=E\left(z_{v} T_{m}\right)\left(\alpha_{0}+\alpha_{1} z^{-1}+\alpha_{2} z^{-2}\right)
\end{gathered}
$$

Solving $U\left(z, T_{m}\right)$ and applying inverse $\mathrm{Z}$ transform to each term of (46), we obtain the recursive equation of the implemented digital PID controller on the MCU of the TWABR control module.

$$
u\left[n T_{m}\right]=\alpha_{0} E\left[n T_{m}\right]+\alpha_{1} e\left[\overline{n-1} T_{m}\right]+\alpha_{2} e\left[\overline{n-2} T_{m}\right]-\ldots
$$

The digital control signal $u\left(n, T_{m}\right)$ is scaled proportionally to deliver the frequency of the PWM signal that feeds the actuation module that drives the stepper motors. Fig. 11 shows the PID architecture implemented in the control module to balance the TWABR system.

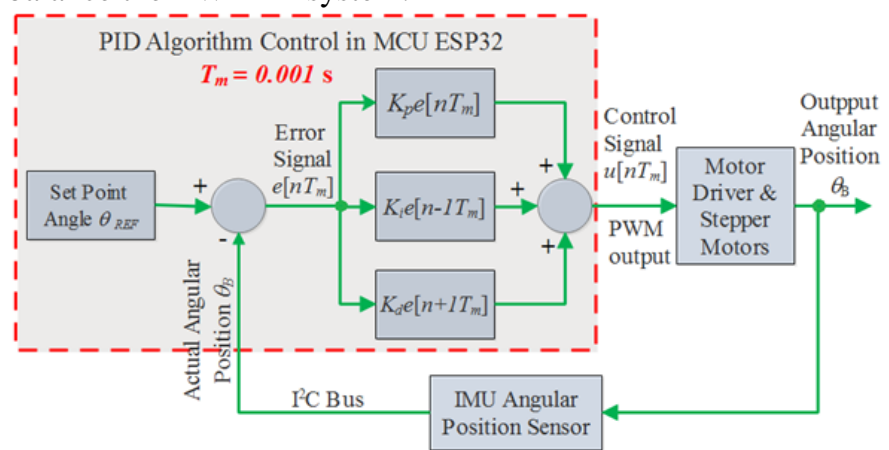

Fig. 11 PID control structure for balancing in vertical position the TWABR.

When reviewing Sisotool of Matlab ${ }^{R}$ the poles location of the feedback TWABR system indicates that the closed loop system is stable with 3 poles located at: $p C L=-35.4 \pm j 6.31$ and -174 .

The dominant poles of the system are $-35.4 \pm j 6.31$, which implies that the feedback controlled system has a second order dynamics where the natural frequency $\omega_{n}$ of this pair of poles is given by the relation (48):

$$
\begin{gathered}
\sigma \pm j \omega=-35.4 \pm j 6.31 \\
\omega_{n}=\sqrt{\sigma^{2}+\omega^{2}} \cong 35.95 \\
f_{n}=\frac{5.06}{2 \pi}=5.72 \mathrm{~Hz}
\end{gathered}
$$

The bandwidth of the system is approximately proportional to the natural frequency of the dominant pole, therefore, the bandwidth of the system is of the order of $6 \mathrm{~Hz}$. The sampling frequency of $1 \mathrm{KHz}$ is much higher than the bandwidth of the closed loop system, causing the control action to be generated fast enough so that the system does not deviate from its vertical position.

Several numerical experiments were performed to test the PID controller. The TWABR was forced to maintain an angle $\theta_{B}=3^{\circ}(0.054$ radians $)$ with $K_{p}=148 ; K_{i}=2960$ and $K_{d}=0.4$.

The TWABR system was initially maintained at the body tilt angle $\theta_{B}=0^{\circ}$, with the reference angle setting set at $\theta_{R E F}=$ $3^{\circ}$. At a time of approximately $t=0.4$ second, the reference angle $\theta_{R E F}$ was abruptly varied from $3^{\circ}$ to $0^{\circ}$. The result of the PID controlled system output reading shows that at approximately 0.7 seconds a disturbance of approximately $2^{\circ}$ occurs, and the system manages to compensate for it.

As seen in Fig. 12, the PID controller responded with an implementable control signal at approximately 0.16 seconds, which is less than 0.2 seconds to meet the specifications. The steady-state error approaches zero quickly. However, the overshoot is around $20 \%$, so to reduce the overshoot it is necessary to increase the value of the differential control action. Faced with the disturbance, the overshoot was around $80 \%$. If the $\theta_{R E F}$ is set negative, the controller moves the TWABR backward to maintain a negative body tilt angle.

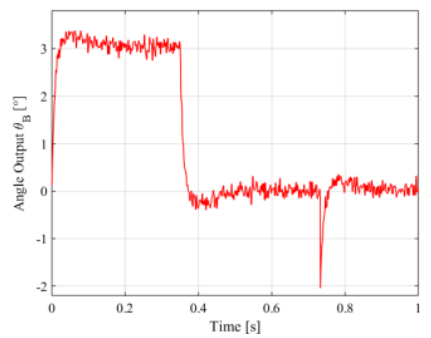

a)

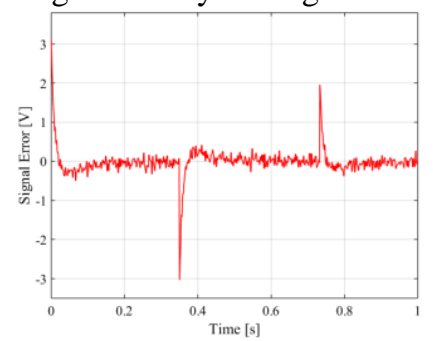

b)
Fig. 12 Simulated results for PID controller implemented. a) Output of the angular position of the TWABR. b) Error signal.

\section{B. LQR Controller Design}

\section{B. LQR Controller Design}

It was proposed to control TWABR through a modern state feedback control using the LQR (Linear Quadratic Regulator) technique. The LQR control finds the optimal gains that multiply each state variable in a state variable feedback structure to meet desired cost specifications. The gains are made by minimizing a cost function. When designing the LQR controller, both the position of the TWABR rotation system and the angle of the main body are considered. If the main body of the TWABR is displaced, the controller will determine the position of the rotation system to make the angle move from the vertical position to zero $\left(\theta_{B}=0\right)$.

Since the LQR is a controller designed in the state space, it is first verified that the representation in the state space of the TWABR system is controllable, performing the controllability test. The system is completely state controllable if and only if the square matrix of controllability $\mathbb{M}_{c}$, which depends on the input matrix $\mathbb{B}$ and the state matrix $\mathbb{A}$, has a complete range, that is, it has a number of linearly independent row vectors equal to the number of state variables. To verify 
controllability, the controllability matrix $\mathbb{M}_{c}$ is calculated, where $\mathbb{M}_{c}=\left[\begin{array}{llll}\mathbb{B} & \mathbb{A} \mathbb{B} & A^{2} \mathbb{B} \ldots \mathbb{A}^{n-1} \mathbb{B}\end{array}\right]$ and obtained from Matlab ${ }^{\circledR}$ with the command $\operatorname{ctrb}()$ and $\operatorname{rank}()$ as 4 , then the system is controllable.

In this case, the system is fully state controllable, and therefore the LQR controller can be designed to calculate the state feedback gain vector $\mathbb{K}$. The structure of the LQR control system is shown in Fig. 13, where the gain vector $\mathbb{K}$ obtained is multiplied by the feedback state variables.

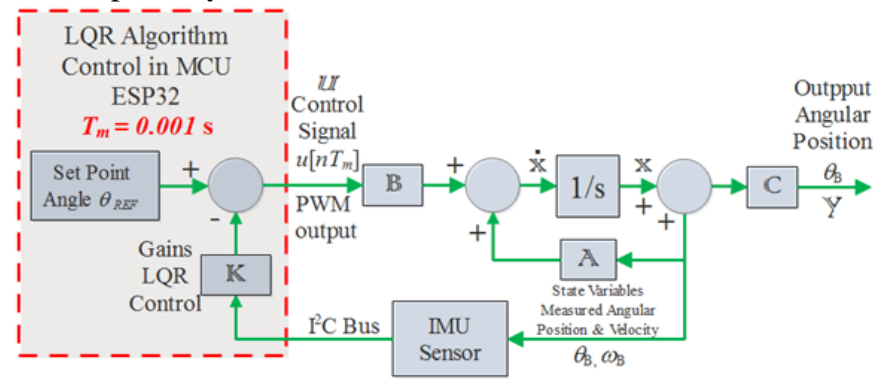

Fig. $13 \mathrm{LQR}$ control structure for balancing in vertical position the TWABR

The Matlab ${ }^{\circledR} \operatorname{lq} r()$ command allows you to choose two parameters $\mathbb{R}$ and $\mathbb{Q}$, which balance the importance or relative weight of the control action $\mathbb{m}$ and the error (deviation from 0) of the state variable respectively, and assign poles to the system to closed loop so that they optimize the cost function I shown in (49).

$$
\mathbb{V}=\int_{0}^{\infty}\left[\mathrm{w}(t) \mathbb{Q n}(t)^{T}+\mathbb{m}(t)^{T} \mathbb{R m}(t)\right] d t
$$

Where $\mathrm{z}(t) \mathbb{Q x}(t)^{T}$ is the cost of the states of the system, $\mathbb{m}(t)^{T} \mathbb{R m}(t)$ is the cost of the control signal, which depend on the weights of the control values with the weights $\mathbb{R}$ and $\mathbb{Q}$. The LQR controller locates the closed-loop poles that balance state errors and the control effect. The basic method for designing the LQR controller is to choose the $\mathbb{R}$ and $\mathbb{Q}$ controller design parameter matrices.

First, the value of $\mathbb{R}$ is initially assumed as 1 to penalize the control signal and $\mathbb{Q}$ is calculated as $\mathbb{Q}=\mathbb{C}^{T} \mathbb{C}$. Then the weight of the matrix $\mathbb{Q}$ is gradually increased or the weight of the matrix $\mathbb{R}$ is decreased to minimize the cost function penalizing the control action or the exit of the system $\left.l=\int\left(y^{2}+u^{2}\right)\right)$.

Then we find the positive semidefinite matrix $\mathbb{P}$ by solving Riccati's algebraic equation, (using Matlab's lqr ()) $\mathbb{A}^{T} \mathbb{P}+\mathbb{P A}+\mathbb{Q}-\mathbb{P} \mathbb{B} \mathbb{R}^{-1} \mathbb{B}^{T} \mathbb{P}=0$. When solving the Ricatti equation, the value of the optimal profit matrix $\mathbb{K}$ is found, using the relation $\mathbb{K}=\mathbb{R}^{-1} \mathbb{B}^{T} \mathbb{P}$. By simulation the parameters are varied until results are obtained that satisfy the design specifications.

$\mathbb{R}$ and $\mathbb{Q}$ values give equal importance to both the control and the output state variable to be controlled which are the TWABR main body angle and the position of the rotation system. The LQR method has the advantage of controlling both outputs.
In the case of the TWABR system, a value of $\mathbb{Q}$ was obtained and $\mathbb{R}=1$ was initially assigned.

$$
\mathbb{Q}=\mathbb{C}^{T} \mathbb{C}=\left[\begin{array}{cccc}
0.5618 & 0 & 0 & 0 \\
0 & 0 & 0 & 0 \\
0 & 0 & 42.34 & 0 \\
0 & 0 & 0 & 0
\end{array}\right]
$$

Then the value of $\mathbb{R}$ was varied to 0.05 to best the responses. Using the $\operatorname{lqr}()$ command in Matlab: $[\mathbb{K}, \mathbb{P}, \mathrm{VP}]=\operatorname{lqr}(\mathbb{A}, \mathbb{B}, \mathbb{Q}, \mathbb{R})$, the optimal gain matrix $\mathbb{K}$ value obtained resulted in: $\mathbb{K}=\left[\begin{array}{lll}2.7930 & 11.0885 & 15.4851\end{array}\right.$ 55.8600]. Fig. 14 shows the response of the LQR controller implemented in the TWABR system, using the same considerations of the PID controller, where a considerable reduction in overshoot is observed compared to the response of the PID.

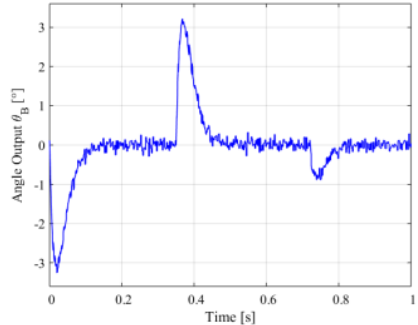

a)

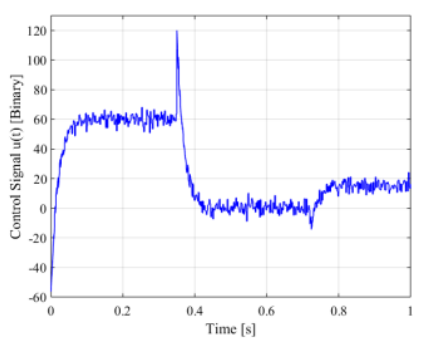

b)
Fig. 14 Simulated results for LQR controller implemented. a) Output of the angular position of the TWABR. b) Control signal.

\section{Comparison of analysis and analysis of results}

Comparing the response of the two controllers shows that running the LQR control is simpler compared to PID control, as it only requires the implementation of two gains that the system output system variables perform to calculate the error and control action. Whereas the PID requires the computation of the recursive equation of the control that requires a computational calculation. The controllers have been designed from the linearized model of the TWABR system that was approximated to its actual behavior.

The analysis and design of the PID control is developed from the transfer function of the system and the LQR controller from its model in the state space. Both parameters meet design specifications with setting times less than 0.2 seconds and TWABR body vertical position less than 5 degrees tilt. But the PID controller has the overshoot problem due to the effect of the integral action being high, however the error in the steady state is small.

The steady state response of the system with the LQR controller had a better transient response, reducing overshoots, and the error in the steady state controller was compensated, however the complexity in its design lies in the solution of the equation of Ricatti. The overall practical performance of the LQR controller compared to the PID controller was better for controlling the vertical position of the TWABR body against disturbances, taking measurements in the direction of falling body faster and smoothly to balance and conserve its vertical position. 


\section{CONCLUSIONS}

This work discussed the design and construction of a functional TWABR system of low cost and size to be used as an experimental didactic tool in the study of control theory in a control course, addressing thematics of modeling and design of digital controllers of nonlinear and unstable systems.

The TWABR system modeling procedure was described using the Lagrange mechanical dynamics equations using the simile with the dynamic behavior of the inverted pendulum.

Since the model of the system was nonlinear, it was linearized and represented mathematically in the state space and in the frequency domain by means of its transfer function, which related the output to the angle of inclination of the TWABR body and with respect to at the input of the angular displacement of the rotation system that is proportional to the torque delivered to the stepper motors to balance it.

As the mathematical model of the TWABR system linearized around its equilibrium point has highly unstable dynamics, two controllers were designed and implemented digitally: a classic PID controller and a Modern LQR controller, in order to stabilize the TWABR system and keep the main body in its vertical position regardless of disturbances.

The design and analysis of the system response against the two implemented control algorithms were simulated using the commands and Toolboxes available from Matlab ${ }^{\circledR}$ / Simulink ${ }^{\mathrm{TM}}$.

The LQR controller presented the best dynamic and static response to the system response, since its performance was faster and without high overshoots, reaching the design specifications proposed as the establishment time less than 0.2 seconds and vertical angle of the body TWABR less than 5 degrees' tilt.

This work is expected to provide the basis for further development and research, such as extending control using the state-space approach to control speed or trajectory tracking and experimentation with a variable tilt angle on actuators.

\section{REFERENCES}

[1] B. Kocaturk, "Motion Control of Wheeled Mobile Robots," Interdisciplinary Description of Complex Systems, Yalova, Turkey, Vol. 13, pp. 41-47, 2015.

[2] F. Grasser, A. D'Arrigo, S. Colombi, and A. Rufer, "JOE: a mobile, inverted pendulum," IEEE Trans. Industrial Electronics, Vol. 49, pp. 107-114, 2001

[3] O. Jamil, M. Jamil, Y. Ayaz, and K. Ahmad, "Modeling, control of a twowheeled self-balancing robot," in Proc. of International Conference on Robotics and Emerging Allied Technologies in Engineering - iCREATE 2014, Islamabad, Pakistan, pp. 1-6, 22-24 April, 2014.

[4] S. Jeong, and T. Takahashi, "Wheeled inverted pendulum type assistant robot: design concept and mobile control," Intelligent Service Robotics, Vol. 1, No. 4, pp.313-320, 2008.

[5] Y. Yoshihiko, S. Ogawa, and S. Machida, "Experiments on step climbing and simulations on inverse pendulum control using robotic wheelchair with inverse pendulum control," Transactions of the Institute of Measurement and Control, Vol., No. 1, pp. 47-61, Feb. 2008.
[6] M. Shino, N. Tomokuni, G. Murata, and M. Segawa, "Wheeled inverted pendulum type robotic wheelchair with integrated control of seat slider and rotary link between wheels for climbing stairs," in Proc.of 2014 IEEE International Workshop on Advanced Robotics and its Social Impacts, Evanston, USA, 11-13 Sept., pp. 121-126, 2014.

[7] T. Takei, R. Imamura, and S. Yuta, "Baggage transportation and navigation by a wheeled inverted pendulum mobile robot," IEEE Transactions on Industrial Electronic, Vol. 56, No. 10, pp. 3985-3994, 2009.

[8] A. Johnson, and A. Nasar, "Design and Development of a Two Wheeled Self Balancing Robot for an Application of Object Carrying," International Journal of Engineering Research \& Technology, Vol. 6, No. 07, pp. 580-587, 2017.

[9] M. Galicki, "Robust task space trajectory tracking control of robotic manipulators," International Journal of Applied Mechanics and Engineering, Vol. 21, No. 3, pp.547-568, 2016.

[10] M. A. Imtiaz, M. Naveed, N. Bibi, S. Aziz, S. Zohaib, and H. Naqvi, "Control System Design, Analysis \& Implementation of Two Wheeled Self Balancing Robot," in Proc. IEEE 9th Annual Information Technology, Electronics and Mobile Communication Conference IEMCON 2018, Vancouver, Canada, pp. 1-6, 1-3 Nov., 2018.

[11] P. Morin, and C. Samson C. Motion Control of Wheeled Mobile Robots. Ed. Springer Handbook of Robotics. Springer, Berlin, Heidelberg A.S., 2008.

[12] T. Turker, H. Gorgun, and G. Cansever, "Lyapunov's direct method for stabilization of the Furuta pendulum," Turkish Journal of Electrical Engineering \& Computer Sciences, vol. 120, No.1, pp. 99-110, 2012.

[13] H. Yun, J. Bang, and J. Kim, "High speed Segway control with series elastic actuator for driving stability improvement," Journal of Mechanical Sciences and Technology, Vol. 33, pp. 5449-5459, 2019.

[14] S. Akiba, T. Zanma and M. Ishida, "Optimal tracking control of twowheeled mobile robots based on model predictive control," in Proc. 11th IEEE International Workshop on Advanced Motion Control - AMC 2010, Nagaoka, Japan, March 21-24, pp. 454-459, 2010.L. Chynoradský, and P. Božek, "Research and development of a new system of the autonomous control of robot trajectory," Acta Mechatronica, Vol. 1, pp. 25-28, 2016.

[15] Y. Dan, P. Xu, Z. Tan, and Z. Li, "Multi mode control base don HSIC for double pendulum robot," JVE International Journal of Vibroengineering, Vol. 17, No. 7, pp. 3683-3692, Nov. 2015.

[16] N. Esmaeili, A. Alfi, and H. Khosravi, "Balancing and Trajectory Tracking of Two-Wheeled Mobile Robot Using Backstepping Sliding Mode Control: Design and Experiments," Journal of Intelligent Robot Systems, Vol. 87, pp. 601-613, 2017.

[17] K. Ogata, Modern Control Engineering, $5^{\text {th }}$ Ed., Boston: Pearson Education, 2009, pp. 70-71.

[18] M. R. Bageant, "Balancing a Two-Wheeled Segway Robot," B..S. Thesis, Massachusetts Institute of Technology, Boston, USA, 2011.

[19] M. Ahmad and H. Osman, "Real-Time Control System for a TwoWheeled Inverted Pendulum Mobile Robot," Advanced Knowledge Application in Practice University Technology, Malaysia, pp. 299-312, Nov, 2015.

[20] Z. Hendzel, and L. Rykala, "Modelling of dynamics of a wheeled mobile robot with mecanum wheels with the use of Lagrange equations of the second kind," International Journal of Applied Mechanics and Engineering, Vol. 22, No. 1, pp. 81-99, 2017.

[21] J. F. Gómez, "Diseño e implementación de un robot auto balanceado," M.S. Thesis, Universidad Politécnica de Valencia, Valencia, España, 2017.

[22] M. W. Spong and D. J. Block, "The Pendubot: a mechatronic system for control research and education," in Proc. of 1995 34th IEEE Conference on Decision and Control, New Orleans, LA, USA, Vol. 1, pp. 555-556, 1995.

[23] W. An and Y. Li, "Simulation and Control of a Two-wheeled Selfbalancing Robot," in Proc. of the IEEE, International Conference on Robotics and Biomimetics - ROBIO 2013, Shenzhen, China, pp. 456461, Dec. 2013. 
[24] Andreyev and O.A. Peregudova, "The motion control of a wheeled mobile robot", Journal of Applied Mathematics and Mechanics, Vol. 79, No. 4, pp. 316-324, 2015.

[25] A. Kharola, P. Patil, S. Raiwani, and D. Rajput, "A comparison study for control and stabilisation of inverted pendulum on inclined surface using PID and fuzzy controllers," Perspectives in Science, Vol.8, pp.187190, 2016.

[26] P. Frankovský, L. Dominik, A. Gmiterko, and I. Virgala, "Modeling of Two-Wheeled Self-Balancing Robot driven by DC Gearmotors," International Journal of Applied Mechanics and Engineering, Vol. 22, No.3, pp. 739-747, 2017

[27] A. Zimit, H. Yap, M. Hamza, I. Siradjuddin, B. Hendrik, and T. Herawan, "Modelling and Experimental Analysis Two-Wheeled Self Balance Robot Using PID Controller," in Proc. of 18th International Conference on Computational Science and Its Applications - ICCSA 2018, Melbourne, Australia, Vol. 1, pp. 683-698, Jul. 2018.

[28] B. G. Zheng, Y. B. Huang, and C. Y. Qiu, "LQR+PID Control and Implementation of Two-Wheeled Self-Balancing Robot," Journal of Applied Mechanics and Materials, Vol. 560, pp. 399-406, 2014.

[29] S. Jiang, F. Dai, L. Li and X. Gao, "Modeling and LQR Control of a Multi-DOF Two-wheeled Robot," in Proc. of the IEEE International Conference on Robotics and Biomimetics - ROBIO 2014, Bali, Indonesia, Dec. 5-10, Vol. 1, pp. 1964-1969, 2014.

[30] J. Fang, "The LQR Controller Design of Two-Wheeled Self-Balancing Robot Based on the Particle Swarm Optimization Algorithm", Conference Proceedings, Vol. 1, pp. 1-6, 25 Feb., 2014.

[31] H. Hellma, \& H. Sunnerman, "Two-Wheeled Self-Balancing Robot, Design and control based on the concept of an inverted pendulum," B.S. Thesis, KTH Royal Institute of Technology, Stockholm, Sweden, 2015.

[32] Espressif Systems, "MCU ESP32 Series Datasheet," Version 3.3, Copyright (C) 2020, [Revised Jan. 2020].

[33] InvenSense Inc., "MPU-6000 and MPU-6050 Product Specification," Revision 3.4, August 2013, [Revised Jan. 2020].

[34] W. Yeadon, and A. Yeadon, Handbook of Small Electric Motors. New York, NY: McGraw-Hill, 2001.

[35] Texas Instruments, "DRV8825 Stepper Motor Controller IC Datasheet," Revision 2014, Jul. 2014, [Revised Jan. 2020].

[36] I. Matesica, M. Nicolae, L. Barbulescu, and A. Margeruseanu, "Selfbalancing robot implementing the inverted pendulum concept," in Proc. of the 15th RoEduNet Conference: Networking in Education and Research, Bucharest, Romania, pp. 1-5, 2016.

[37] F. Kung, "A Tutorial on Modelling and Control of Two-Wheeled SelfBalancing Robot with Stepper Motor," Applications of Modelling and Simulation, Vol. 3, No. 2, pp. 64-73, 2019.

[38] P. Strakos and J. Tuma, "Mathematical Modelling and Controller Design of Inverted Pendulum," in Proc of the. 18th International Carpathian Control Conference - ICCC, Sinaia, Romania, pp. 388-393, 2017.

[39] Z. G. Morteza, "A constructive self-balancing controlled Lagrangian for wheeled inverted pendulum," in Chinese Control and Decision Conference (CCDC), Yinchuan, China, pp. 1776-1781, 2016.

[40] D. Pratama, E. Henfri, and F. Ardilla, "Movement Control of Two Wheels Balancing Robot using Cascaded PID Controller," in Proc. International Electronics Symposium (IES), Surabaya, Indonesia, pp. 345-349, 2015.

[41] A. J. Abougarair, and E. S. Elahemer, "Balancing Control of Two Wheeled Mobile Robot Based on Decoupling Controller," International Journal of Control Systems and Robotics, Vol. 3, pp. 1-7, 2018.

[42] H. Niu, N. Wang and N. Li, "The adaptive Control Based on BP Neural Network Identification for Two Wheeled Robot," in Proc. 12th World Congress on Intelligent Control and Automation - WCICA 2016, 12-15 June 12-15, Guilin, China, pp. 2437-2442, 2016.

[43] A. I. Glushchenko, V. A. Petrov, \& K. A. Lastochkin, "On Development of Neural Network Controller with Online Training to Control TwoWheeled Balancing Robot", in Proc. Automation Conference (RusAutoCon) 2018 International Russian, pp. 1-6, 2018.

18 $^{\text {th }}$ LACCEI International Multi-Conference for Engineering, Education, and Technology: "Engineering, Integration, and Alliances for a Sustainable Development" "Hemispheric Cooperation for Competitiveness and Prosperity on a Knowledge-Based Economy", 29-31 July 2020, Buenos Aires, Argentina. 